\title{
The Evaluation of Researches Related to Problem Based Learning in Teacher Education*
}

\author{
Ramazan YURTSEVEN **
}

\author{
Aytunga OĞUZ ***
}

Accepted: 08 July 2015

\begin{abstract}
The purpose of this research is to evaluation of the researches related to the problem-based learning (PBL) in teacher education in Turkey. A case study method was used in this study. Its population consists of the 23 articles, 11 master and 16 doctoral theses that made related to problem-based learning in teacher education between the years of 2002-2013 in Turkey. The researches were investigated the distributions in terms of "type, publication year, sample characteristics, models, data collection methods and tools, the variables studied and the data obtained". The data were evaluated by calculating the percentage and frequency values. According to the findings; It is observed that the researches intensified especially in the last five years, the majority of them were carried out with students, they were carried out most of the researches in program of Science Education. It is observed that experimental models were mostly used as model, mixed (qualitative and quantitative) methods were used as data collection methods and mostly surveys were used as means of data collection. Mostly that was studied by variables of academic achievement, attitude, scientific treatment process and problem-solving skills. It is observed that PBL has mostly positive effects on these variables. In line with these findings, some of the proposals may contribute to future researches have been developed.
\end{abstract}

Keywords: problem-based learning; teacher training; scientific research

\section{Extended Abstract}

Purpose and Significance: In the learning environments, with constructivist approach, one method that effectively allows the students to learn is problem-based learning (PBL). However, in order to use this method effectively, teachers must have gained the necessary knowledge and skills in teacher education programs. In this context, there are various studies conducted on the PBL in Turkey. However, made on problem-based learning in teacher education was not observed to any evaluation. So, in this study, it is aimed to evaluation of the researches related to the PBL in teacher education in Turkey. In addition to this general purpose, it has been sought to answer the following questions:

- How is the distribution in terms of the kind and year of publication of these researches?

\footnotetext{
* This study was presented as oral presentations in National Classroom Teaching Symposium which was carried out between 29-31 May 2014.

**Corresponding Author: Teacher, Nene Hatun Primary School, İstanbul, Turkey, ramazan_yurtseven15@hotmail.com

*** Assoc. Prof. Dr., Dumlupinar University, Kütahya, Turkey, aytunga.oguz@dpu.edu.tr
}

\section{Citation Information}

Yurtseven, R. \& Oğuz, A. (2016). Öğretmen eğitiminde probleme dayalı öğrenmeye ilişkin yapılan araştırmaların değerlendirilmesi. Kuramsal Eğitimbilim Dergisi [Journal of Theoretical Educational Science], 9(2), 266-284. 
- How is the distribution in terms of characteristics of the study sample of these researches?

- How is the distribution in terms of models and methods of these researches?

- How is the distribution in terms of data collection tools and techniques of these researches?

- How is the distribution in terms of the studied variables and reached the findings of these researches?

Methods: A case study model is used in this study. Its population consists of the articles, master and doctoral theses that made related to problem-based learning in teacher education between the years of 2002-2013 in Turkey. 23 articles, 16 doctoral and 11 master theses for a total of 50 studies can be reached on this issue were examined. The researches that reached related to the problem-based learning (PBL) in teacher education were investigated the distributions in terms of "type, publication year, sample characteristics, models, data collection methods and tools, the variables studied and the data obtained". The resulting data were transferred to statistical software package and were evaluated by calculating the percentage and frequency values.

Results: According to the findings; nearly half of researches related to the problembased learning (PBL) in teacher education has been performed as articles. It is observed that doctoral theses (16) are greater than he master's theses (11) on this subject. It is determined that the researches intensified especially in the last five years. The majority of studies were carried out with students in teacher education programs (88\%), studies were carried out with students of 1 st class (24\%) and 3rd class (28\%) are higher than the others. It is observed that were carried out most of the researches in Science Education (32\%) Section in 44 studies conducted with students; but has never been carried out in Art, Physical Education, History, Geography, Biology and Pre-School Education programs. It is observed that is mostly used to experimental models (68\%) and is used together (22\%) qualitative and quantitative (mixed) data collection methods. As a means of data collection, mostly surveys (62\%) were used. At most of the researches, PBL was studied by variable of academic achievement (58\%), attitude (38\%), scientific treatment process (26) and problem-solving skills (22\%). However, the researches with regard variables of motivation (10\%), self-efficacy beliefs (12\%), retention (10\%) and creativity (14\%) were found to be less. In the researches with regard this variables, it can be said that PBL has mostly positive effects and hasn't the negative effects.

Discussion and Conclusions: As a result, it is observed that the researches intensified especially in the last five years. It may be due to the following that began to adopt a constructivist approach since 2005 in Turkey. In this respect, in teacher education at last years in Turkey, have been pointed to the benefits of constructivist learning experiences and positive impact on teacher candidates (Bukova-Güzel, 2008; Kardaş, 2014; Oğuz, 
2009). It is observed that the majority of them were carried out with students and they were carried out most of the researches in program of Science Education. It is observed that experimental models were mostly used as model. Similarly, in research of B1kmaz Hazır, Aksoy and Tatar (2010), experimental and descriptive studies revealed that more preferred. It is observed that mixed (qualitative and quantitative) methods were used as data collection methods and mostly surveys were used as means of data collection. These results are similar to researches of Kazu and Aslan (2013) and Saracaloğlu and Dursun (2010). Mostly that was studied by variables of academic achievement, attitude, scientific treatment process and problem-solving skills. It is observed that PBL has mostly positive effects on these variables. Similarly, in the research carried out by Karadağ (2009), it was concluded that the focus of theme of achievement and attitudes in the doctoral thesis of the field of educational sciences in Turkey. In line with these findings, some of the proposals may contribute to future researches have been developed. 


\title{
Öğretmen Eğitiminde Probleme Dayalı Öğrenmeye İlişkin Yapılan Araştırmaların Değerlendirilmesi*
}

\author{
Ramazan YURTSEVEN ${ }^{* *}$
}

\author{
Aytunga OĞUZ ${ }^{* * *}$
}

Makale Gönderme Tarihi: 08 Nisan 2015

Makale Kabul Tarihi: 08 Temmuz 2015

\begin{abstract}
ÖZ: Bu araştırmada, Türkiye'de öğretmen eğitiminde probleme dayalı öğrenmeye (PDÖ) ilişkin yapılan araştırmaların değerlendirilmesi amaçlanmıştır. $\mathrm{Bu}$ araştırmada iç içe geçmiş durum deseni kullanılmıştır. Araştırmanın evrenini, 2002-2013 yılları arasında Türkiye’de öğretmen eğitiminde PDÖ’ye ilişkin yapılan 23 makale, 11 yüksek lisans tezi ve 16 doktora tezi oluşturmaktadır. Bu araştırmaların; "tür, yayın yıll, örneklem özellikleri, model, veri toplama yöntemi ve araçları, çalışılan değişkenler ve ulaşılan bulgular” açısından dağılımları incelenmiş, veriler, yüzde ve frekans değerleri hesaplanarak değerlendirilmiştir. Bulgulara göre, araştırmaların; özellikle son beş yılda yoğunlaştığı, çoğunluğunun öğrencilerle gerçekleştirildiği ve en çok Fen Bilgisi Öğretmenliği programında yapıldığı görülmüştür. Araştırmalarda model olarak daha çok deneysel model, veri toplama yöntemi olarak karma (nitel ve nicel) yöntem ve veri toplama aracı olarak en çok ölçek kullanıldığı görülmüştür. Bu konu araştırmalarda çoğunlukla "akademik başarı, tutum, bilimsel işlem süreci, problem çözme becerisi" değişkenleriyle çalışılmış ve PDÖ’nin bu değişkenler üzerinde genellikle olumlu etkiler bıraktığı görülmüştür. Bu sonuçlar doğrultusunda, ileride yapılacak araştırmalara katkı sağlayabilecek bazı öneriler geliştirilmiştir.
\end{abstract}

Anahtar kelimeler: probleme dayalı öğrenme; öğretmen eğitimi; bilimsel araştırma

\section{Giriş}

Öğretim ortamlarında uygulanan yöntemler öğrencilerin neleri nasıl öğrenebileceklerini önemli ölçüde etkileyebilmektedir. Son yıllarda, öğretmenin etkin olduğu öğrenme ortamlarında öğrencinin, birçok bilgiyi ezberlemesi yerine; yeni bilgileri ön bilgileriyle bütünleştirmesini, anlamlandırmasını ve kullanmasını sağlayan öğrenci merkezli, demokratik, yapılandırmacı öğrenme ortamlarında öğrenmesi giderek önem kazanmıştır. Bu süreçte öğretmenin; öğrenciyi etkin kılması, ona özerklik tanıması ve bilgiyi yapılandırmasına yardım etmesi; öğrencinin de öğrenme sorumluluğunu üstlenerek etkin bir biçimde öğrenme çabalarında bulunması gerekmektedir (Brooks \& Brooks, 1999; Gagnon \& Collay, 2001; Jofili, Geraldo \& Watts, 1999; Olsen, 1999; Plourde \& Alawiye, 2003; Tynjälä, 1999; Windschitl, 1999; Yager, 1991).

Yapılandırmacı öğrenme ortamlarında, öğrencilerin etkin bir biçimde öğrenmelerini sağlayabilecek yöntemlerden birisi probleme dayalı öğrenmedir (PDÖ) (Gabler \& Schroeder, 2003; Jonassen, 2006; McPhee, 2002; Simone, 2008). Bu yöntem, öğrencilere, problemlere dayalı bağlamlarda, araştırarak ve öğrenme sorumluluğu alarak öğrenme olanağı vermektedir (Demirel \& Arslan Turan, 2010). Öğrenciler, problem çözme sürecinde, konu alanı bilgisi ve duruma uygun bilişsel stratejileri seçip kullanarak amaca ulaşabilir; başka bir deyişle, problemi çözebilirler (Senemoğlu, 2013). Bu durumda, problemin çözülebilmesi için öğrencinin amaç araç ilişkisini kurabilmesi gerekmektedir. Bu nedenle, öğrenenin bu süreçte etkin çaba

\footnotetext{
* Bu çalışma, 29-31 Mayıs 2014 tarihleri arasında gerçekleştirilen XIII. Ulusal Sınıf Öğretmenliği Sempozyumu'nda sözlü bildiri olarak sunulmuştur.

** Sorumlu Yazar: Sınıf Öğretmeni, Nene Hatun İlkokulu, İstanbul, Türkiye, ramazan_yurtseven15@hotmail.com

**** Doç. Dr., Dumlupınar Üniversitesi, Kütahya, Türkiye, aytunga.oguz@dpu.edu.tr
} 
göstermesi, öğretmenin de onun, amaca ulaşmasını sağlayacak aracı bulup kullanmasına rehberlik etmesi gerekmektedir. PDÖ ortamlarında, öğrenciler, karmaşık gerçek yaşam problemleriyle karşı karşıya gelerek problemlerin çözümünü araştırarak öğrenmektedirler. Öğretmenlerin görevi ise bu süreçte onlara bilişsel rehberlik etmektir (Saban, 2009).

Probleme dayalı öğrenme sürecinde öncelikle amaca uygun, nitelikli bir problemin belirlenmesi daha sonra da belirlenen problemin çözümü için gerekli adımların atılması gerekmektedir. Öğrenciler, gerekli adımları öğretmenlerinin rehberliğinde atarak problemi etkin bir biçimde çözebilirler. Alanyazında PDÖ sürecinde izlenebilecek basamaklarla ilgili olarak çeşitli sıralamalar yapılmaktadır (Kaptan \& Korkmaz, 2001). Örneğin; hem tek doğru cevaplı problemlerin hem de çok boyutlu problemlerin çözümü için genel olarak; önce problemin anlaşılması, sonra çözümü için plan yapılması, daha sonra da bu planın uygulanması ve sonuçlarının değerlendirilmesi basamaklarının izlenmesinin uygun olabileceği belirtilmektedir (Polya, 1957, Eggen \& Kauchak, 1992, 538'den Akt. Senemoğlu, 2013). Maxwell, Bellisimo \& Mergendoller (2001: 74) de genel bir PDÖ modelinde izlenebilecek aşamaları şöyle sıralamaktadır:

1. Öğrencinin, çalı̧̧maya başlamadan ya da herhangi bir hazırlık yapmadan önce, öğrenmeye teşvik edici bir problem durumuyla karşı karşıya getirilmesi.

2. Öğrencilerin, küçük gruplarda öğretmenin rehberliğinde, gerçek dünyadakine benzer tarzda sunulmuş olan problem durumunu çözmeye yönlendirilmeleri.

3. Öğrenciler yetenekleri doğrultusunda problemi çözmeye çalışırken öğretmenin sorular sorarak ve öğrenme sürecini izleyerek öğrenmeyi kolaylaştırması.

4. Öğrenme süreci boyunca gereksinimlerin belirlenmesi ve çalışmaların bireyselleştirilmesine rehberlik etmek için kullanılması

5. Daha önce, 3. ve 4. adımlarda kazanılan bilgi ve becerilerin problem üzerindeki etkililiğinin değerlendirilmesi, öğrenmenin pekiştirilmesi ve bağlamlaştırılması.

6. Bu süreçte oluşan öğrenmenin öğrencinin ön bilgisiyle bütünleştirilmesi.

$\mathrm{Bu}$ aşamalar PDÖ ortamlarında etkili bir biçimde düzenlendiğinde amaca ulaşılabilir ve yarar sağlayabilir. Bu nedenle, öğrencilerin problemi çözmek için hangi adımları atmaları gerektiğini ve bu adımlarda neler yapmaları gerektiğini bilmeleri gerekmektedir. $\mathrm{Bu}$ süreçte öğrencilerin ön bilgilerini kullanarak yeni bilgiler oluşturmalarına yardım edilmelidir. Öğrenciler; araştırmaya, kaynakları tamamlamaya, öğrendiklerini birbirleriyle paylaşmaya ve kendi öğrenmelerinin sorumluluğunu taşımaya yöneltilebilirler (Ün Açıkgöz, 2002). Böylece, PDÖ ortamları öğrencilere birçok yarar sağlayabilir. PDÖ, öğrencilerin ön öğrenmelerinin ortaya çıkmasını, gerçek yaşamlarında karşılaşabilecekleri bağlamlarda öğrenmenin gerçekleşmesini; bilginin, düzenlenmesini ve anlamlandırılarak kalıcı bir biçimde kazanılmasını sağlamaktadır (Erdem, 2007). Alanyazında PDÖ’nin öğrencilerin başarılarını (Alagöz, 2009; Erdoğan, 2012) ve öz yeterlik algı düzeylerini artırdığı (Erdem, 2006); gelişimlerini sağladığı 
(Fettahoğlu, 2012), etkin öğrenme ortamı oluşturduğu, motivasyonu ve bilgilerin kalıcılığını sağladığı ve öğrencilerin araştırma becerilerini geliştirdiği (Çelik, 2013) gibi yararlarından da söz edilmektedir.

Öğretmen eğitiminde de PDÖ’nin, iletişim becerilerinde güveni artırdığı, meslekte karşı karşıya gelinebilecek sorunların farkına varılmasını ve kuram ile uygulamanın ilişkilendirilmesini sağladığı belirtilmektedir (Edwards \& Hammer, 2006; Patrick \& Mcphee, 2014). Bununla birlikte bu yöntem öğrenme ortamlarında, motivasyonu artırma, kontrolü ve disiplini sağlama gibi konularda da yararlar sağlayabilmektedir. Örneğin PDÖ’yi uygulayan bir öğretmen, bir senaryo sayesinde öğrencilerine, sosyal ve toplumsal sorunların çözümünde ve birçok durumlarda olumlu davranışlar kazandırmayı başarabilir (McPhee, 2002). Bu noktada öğrencileri; problem çözebilen, araştıran, sorgulayan ve öğrenmeyi öğrenen bireyler olarak yetiştirebilmek için, öğretmenlerin PDÖ ortamları düzenleyebilmeleri ve öğrencilere rehberlik edebilmeleri önem taşımaktadır. Bu nedenle, PDÖ'nin basamaklarını amacına uygun bir şekilde uygulayabilecek bilgi ve beceriye sahip öğretmenlerin yetiştirilmesi gerekmektedir. Buna göre, öğretmen eğitimi programlarında öğretmen adaylarına gerekli bilgi ve beceriler PDÖ ortamlarında uygulamalı olarak kazandırılabilir. Öğretmen adayları mesleğe başlamadan önce PDÖ ortamlarında yetiştirilirse hem bilgi ve becerileri etkili ve kalıcı bir biçimde kazanabilirler hem de gelecekte öğrencilerine bu ortamları kolaylıkla düzenleyebilirler.

Türkiye'de öğretmen eğitiminde PDÖ konusunda yapılmış çeşitli çalışmalar bulunmaktadır (Alagöz, 2009; Çelik, 2013; Erdem, 2006; Erdoğan, 2012; Erdoğan \& Fettahoğlu, 2012; Senemoğlu, 2014; Şendağ, 2008). Ancak, öğretmen eğitiminde probleme dayalı öğrenme ile ilgili yapılan araştırmaların analiz edildiği ve değerlendirildiği bir çalışmaya rastlanmamıştır. Öğretmen eğitiminde PDÖ ile ilgili birbirinden bağımsız olarak yapılan çalışmaların özelliklerinin değerlendirilip yorumlanması bu konuda yapılabilenlerin ve yapılamayanların ortaya konulabilmesi, bu konudaki eğilimin belirlenebilmesi açısından önem taşımaktadır. Öğretmen eğitiminde PDÖ ile ilgili yapılmış çalışmaların değerlendirilmesi, bu gereksinimin giderilmesini sağlayabilir. Bununla birlikte, araştırmada elde edilen sonuçların Türkiye'de öğretmen eğitiminde PDÖ ile ilgili yapılan araştırmaların genel bir tablosunu ortaya koyarak bu konuda gelecekte yapılacak çalışmalara da katkı sağlayabileceği düşünülmektedir. Bu düşüncelerden hareketle, bu çalışmada, Türkiye'de öğretmen eğitiminde PDÖ ile ilgili yapılmış çalışmaların değerlendirilmesi amaçlanmıştır. Bu genel amaç doğrultusunda aşağıdaki sorulara cevap aranmıştır:

Türkiye’de öğretmen eğitiminde PDÖ ile ilgili yapılmış araştırmaların;

1. Türü ve yayın yılı açısından dağılımları nasıldır?

2. Örneklem özellikleri açısından dağılımları nasıldır?

3. Model ve yöntemleri açısından dağılımları nasıldır?

4. Veri toplama araçları ve teknikleri açısından dağılımları nasıldır?

5. Çalışılan değişkenler ve ulaşılan bulgular açısından dağılımları nasıldır? 


\section{Sinırlılıklar}

1. Bu çalışma, 2002-2013 yılları arasında Türkiye'de öğretmen eğitiminde PDÖ’ye ilişkin yapılan makale, yüksek lisans ve doktora tezleri ile sınırlandırılmıştır.

2. "Probleme dayalı öğrenme" "öğretmen yetiştirme”, “öğretmen eğitimi” "probleme dayalı öğrenme-öğretmen yetiştirme" gibi anahtar kelimeler kullanılarak ULAKBİM, YÖK, Google Akademik veritabanlarında yapılan tarama sonucunda ulaşılan araştırmalarla sınırlıdır.

3. İncelenen çalışmalar, amaçlarda belirtilen boyutlardaki dağılımları ile sınırlandırılmıştır. Araştırmada incelenen çalışmalar, yöntembilimsel olarak ayrıntılı bir şekilde ele alınmamıştır.

\section{Yöntem}

\section{Araştırmanın Modeli}

$\mathrm{Bu}$ araştırma, nitel araştırma modellerinden durum çalışması ile gerçekleştirilmiştir. Çalışmanın deseni iç içe geçmiş çoklu durum çalışmasıdır. Bu desende "ele alınan veya araştırmaya dâhil edilen her bir durum, kendi içinde çeşitli alt birimlere ayrılarak” çalışılmaktadır (Yıldırım \& Şimşek, 1999, 205). Bu araştırmada da, PDÖ konusunda Türkiye'de yapılan araştırmalardan İnternet ortamında ulaşılabilen eğitim dergilerinde yayımlanan makaleler ve Ulusal Tez Merkezi'nden ulaşılan tezler araştırmanın amaçları açısından alt birimlere ayrılmış analiz edilmiş ve var olduğu şekliyle değerlendirilmeye çalışılmıştır.

\section{Evren-Örneklem}

Araştırmanın evrenini, 2002-2013 yılları arasında, Türkiye'de öğretmen eğitiminde PDÖ konusunda yapılmış makale, yüksek lisans ve doktora tezleri oluşturmaktadır. Evren üzerinde gerçekleştirilen araştırmada, «Probleme dayalı öğrenme, öğretmen yetiştirme, “öğretmen eğitimi, probleme dayalı öğrenme-öğretmen yetiştirme» anahtar sözcükleriyle ulaşılabilen; 23 makale, 11 yüksek lisans tezi ve 16 doktora tezi olmak üzere toplam 50 çalışma incelenmiştir.

\section{Verilerin Toplanması ve Analizi}

Araştırmada, 2002-2013 yılları arasında Türkiye'de öğretmen eğitiminde probleme dayalı öğrenmeye ilişkin yapılan makaleler, yüksek lisans ve doktora tezleri bir araya getirilerek genel bir değerlendirmeye gidilmeye çalışılmıştır. Bu amaca yönelik ulusal ve uluslararası dergilerde yayınlanmış makalelere, YÖK Ulusal Tez Merkezinden erişilebilen yüksek lisans ve doktora tezlerine ulaşılmaya çalışılmıştır. Verilerin analizinde doküman analizi tekniği kullanılmıştır. Buna göre, internet ortamında "probleme dayalı öğrenme" "öğretmen yetiştirme”, "öğretmen eğitimi” "probleme dayalı öğrenme-öğretmen yetiştirme" gibi anahtar kelimeler kullanılarak yapılan tarama sonucunda, özellikle probleme dayalı öğrenmeyle ilgili ilköğretim ve ortaöğretim düzeyinde birçok araştırmaya ulaşılmış ancak öğretmen yetiştirmeyle ilgili 
olmayanlar elenmiştir. Diğer taraftan, 2002-2013 yılları arasında olmayan, makale ve tez haricindeki çalışmalara yer verilmemiştir. Tez aynı zamanda makale olarak da yayınlanmışsa makale değerlendirilmiştir. Verilerin kodlanması aşamasında öncelikle yukarıdaki ölçütlere uygun özellikleri taşıyan araştırmalar bir dosyaya toplanmış, sayı numarası verilerek yazar adlarıyla birlikte kayıt edilmiştir. Kaydedilen her bir araştırma Microsoft Excel çalışma sayfasında sayı numarası ve yazar isimlerine göre listelenmiştir. Herhangi bir karışıklığa sebep olmaması için sayı numarası-yazar isimleri ile dosyalar arasında bağlantı kurularak istenilen araştırmaya kolaylıkla ulaşılması sağlanmıştır. Araştırmanın amaçları doğrultusunda her bir çalışmaya ilişkin kategorik veriler Microsoft Excel dosyasındaki ilgili sütunlara kodlanmıştır. Ulaşılan araştırmalar aşağıda belirtilen başlıklar altında sınıflandırılarak incelenmiştir:

1. Araştırmanın Türü (Makale, Yüksek Lisans Tezi, Doktora Tezi)

2. Yayın Y1lı (2002-2013 yılları arası)

3. Çalışma Grubu Özellikleri

3a. Hedef Kitle (Öğrenci, Öğretmen)

3b. Öğretim Programları (Okul Öncesi, Sınıf, Türkçe, Matematik, İngilizce, Sosyal Bilgiler, Fen Bilgisi, Resim, Müzik, Beden, Tarih, Coğrafya, Fizik, Kimya, Biyoloji, Ortak Gruplar, Belirtilmemiş)

3c. Çalışma Grubunun Sınıf Düzeyi (Üniversite 1, 2, 3, 4. 5.sınıfları, Ortak sınıflar, Belirtilmemiş)

4. Yöntem ve Model (Betimsel/tarama, deneysel, nicel, nitel, nitel ve nicel, belirtilmemiş)

5. Veri Toplama Araçları (Ölçek, görüşme, ölçek ve görüşme, gözlem, diğer değerlendirme araçları)

6. Bulgular (Akademik Başarı, Motivasyon, Tutum, Problem Çözme Becerisi, Öz-Yeterlilik İnancı, Bilimsel İşlem Süreci, Yaratıcılık, Kalıcılık)

$\mathrm{Bu}$ başlıklar altında kodlanan verilerin güvenirliğini sağlamak için bir süre sonra öncekilerden bağımsız olarak veriler birinci araştırmacı tarafından ikinci kez kodlanmıştır. Kodlanan araştırmalar yukarıda belirtilen kategoriler çerçevesinde incelenmiş, yüzde ve frekans değerleri hesaplanmıştır. Elde edilen veriler bulgular kısmında tablolara dönüştürülerek sunulmuştur.

\section{Bulgular}

Çalışma sonucunda, 2002-2013 yılları arasında öğretmen eğitiminde PDÖ’ye ile ilgili yapılmış araştırmalardan elde edilen bulgular, amaçlar doğrultusunda analiz edilerek aşağıda sunulmuştur. Bulguların sunumunda araştırmanın amacı ile ilgili soruların sırası izlenmiştir. Çalışma kapsamına alınan araştırmaların analizleri tablolar halinde gösterilmiştir.

Türkiye'de öğretmen eğitiminde PDÖ ile ilgili yapılmış araştırmaların tür ve yayın yılı açısından dağılımları belirlenmiş ve Tablo 1'de sunulmuştur. 
Tablo 1

Araştırmaların Tür ve Yayın Yılı Açısından Dă̆glımı

\begin{tabular}{|c|c|c|c|c|c|c|c|c|c|c|c|c|c|c|}
\hline \multirow[b]{2}{*}{$\begin{array}{l}\text { Araştırma } \\
\text { Türü }\end{array}$} & \multicolumn{14}{|c|}{ Yayın Yılları } \\
\hline & ำ & ֻ̊̊ి & ঠి & 농 & ஜ̊ & ڤิ) & $\stackrel{\infty}{\circ}$ & ஓे & $\stackrel{\circ}{\stackrel{2}{2}}$ & 궁 & 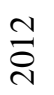 & $\stackrel{m}{\stackrel{\sim}{\sim}}$ & $f$ & $\%$ \\
\hline Makale & 1 & - & - & 4 & 1 & 2 & 2 & 2 & 2 & 4 & 5 & - & 23 & 46 \\
\hline $\begin{array}{l}\text { Yüksek } \\
\text { Lisans Tezi }\end{array}$ & - & - & 1 & - & - & - & 1 & 4 & 3 & 2 & - & - & 11 & 22 \\
\hline $\begin{array}{l}\text { Doktora } \\
\text { Tezi }\end{array}$ & - & 1 & - & 1 & 1 & 3 & 2 & 2 & 1 & 2 & 2 & 1 & 16 & 32 \\
\hline Toplam & 1 & 1 & 1 & 5 & 2 & 5 & 5 & 9 & 6 & 7 & 7 & 1 & 50 & 100 \\
\hline
\end{tabular}

Tablo 1'de görüldüğü gibi, 2002-2013 y1lları arasında öğretmen eğitiminde probleme dayalı öğrenmeye yönelik yapılmış 23 makale (\%46), 11 yüksek lisans tezi (\%22) ve 16 doktora tezi (\%32) bulunmaktadır. PDÖ ile ilgili çalışmaların yarıya yakını makale olarak, yaklaşık dörtte biri yüksek lisans tezi, üçte biri ise doktora tezi olarak gerçekleştirilmiştir. Araştırmaların, 2006 yılında daha az olduğu görülmekle beraber, 2005-2012 yılları arasında yoğunlaştığ söylenebilir. Bu konuda, 2002-2004 y1lları arasında yapılmış birer çalışmaya ulaşılmış; 2013 yılında ise sadece bir çalışmaya rastlanmıştır.

Türkiye'de öğretmen eğitiminde PDÖ ile ilgili yapılmış araştırmaların örneklem özellikleri açısından dağılımları incelenmiş ve Tablo 2'de sunulmuştur. İncelemeye alınan araştırmaların tamamına yakını (\%88) öğrencilerle (öğretmen adaylarıyla) gerçekleştirilmiştir. Ancak sadece iki (\%4) araştırma öğretmenlerle gerçekleştirilmiş, dört (\%8) araştırmanın da doküman incelemesi ya da kuramsal olarak yapıldı̆̆ 1 belirlenmiştir. 
Tablo 2

Araştırmaların Örneklem Özellikleri Açısından Dă̆ılımı

\begin{tabular}{|c|c|c|c|}
\hline & Değişkenler & $f$ & $\%$ \\
\hline \multirow{3}{*}{ Çalışma Grubu } & Öğretmen & 2 & 4 \\
\hline & Öğrenci & 44 & 88 \\
\hline & Kuramsal & 4 & 8 \\
\hline \multirow{20}{*}{$\begin{array}{l}\text { Çalışma Grubunun } \\
\text { Öğrenim Alanları }\end{array}$} & Okul Öncesi Öğretmenliği & - & 0 \\
\hline & Sınıf Öğretmenliği & 8 & 16 \\
\hline & Türkçe Öğretmenliği & 2 & 4 \\
\hline & Matematik Öğretmenliği & 6 & 12 \\
\hline & İngilizce Öğretmenliği & 2 & 4 \\
\hline & Sosyal Bilgiler Öğretmenliği & 2 & 4 \\
\hline & Fen Bilgisi Öğretmenliği & 16 & 32 \\
\hline & Resim Öğretmenliği & - & 0 \\
\hline & Müzik Öğretmenliği & 1 & 2 \\
\hline & Beden Eğitimi Öğretmenliği & - & 0 \\
\hline & Tarih Öğretmenliği & - & 0 \\
\hline & Coğrafya Ö̆gretmenliği & - & 0 \\
\hline & Fizik Öğretmenliği & 2 & 4 \\
\hline & Kimya Öğretmenliği & 2 & 4 \\
\hline & Biyoloji Öğretmenliği & - & 0 \\
\hline & PDR & 1 & 2 \\
\hline & Ortak 1(Türkçe-Matematik Öğretmenliği) & 1 & 2 \\
\hline & Ortak 2(Matematik-Kimya Öğretmenliği) & 1 & 2 \\
\hline & Ortak 3(Fen Bilgisi-Kimya Öğretmenliği) & 1 & 2 \\
\hline & Belirtilmemiş & 5 & 10 \\
\hline \multirow{8}{*}{$\begin{array}{l}\text { Çalışma Grubunun } \\
\text { Sınıf Düzeyi }\end{array}$} & 1.Sinif & 12 & 24 \\
\hline & 2.Sinif & 7 & 14 \\
\hline & 3.Sinıf & 14 & 28 \\
\hline & 4.Sinıf & 3 & 6 \\
\hline & Ortak 1 (1 ve 2. Sinıf) & 1 & 2 \\
\hline & Ortak 2 (4 ve 5. Sinıf) & 1 & 2 \\
\hline & Belirtilmemiş & 12 & 24 \\
\hline & Toplam & 50 & 100 \\
\hline
\end{tabular}


Tablo 2'de görüldüğü gibi, incelenen araştırmalarda örneklem grubu olarak öğrencilerle yürütülen 44 çalışmanın en çok Fen Bilgisi Öğretmenliğinde (\%32) yapıldığı; bunu, Sınıf Öğretmenliği (\%16) ve Matematik Öğretmenliği (\%12) programlarının izlediği görülmektedir. Ancak Resim Öğretmenliği, Beden Eğitimi Öğretmenliği, Tarih Öğretmenliği, Coğrafya Öğretmenliği, Biyoloji Öğretmenliği, Okul Öncesi Öğretmenliği programlarında bu konuda bir araştırma yapılmamıştır. Türkçe Öğretmenliği, İngilizce Öğretmenliği, Sosyal Bilgiler Öğretmenliği ve Fizik Öğretmenliği programlarında ise ikişer araştırma bulunmaktadır. Araştırmaların tamamına yakınının (42) sadece bir programa devam eden öğrencilerle gerçekleştirildiği, üç çalışmanın iki farklı programın öğrencileriyle birlikte gerçekleştirildiği ve beş araştırmada ise öğrencilerin öğrenim gördüğü programın belirtilmediği görülmüştür. Ayrıca, öğretmenlerle gerçekleştirilen iki çalışmanın Sınıf öğretmenleriyle ve Matematik öğretmenleriyle gerçekleştirildiği belirlenmiştir.

Araştırmaların incelenmesi sonucunda, 1. sınıf (\%24) ve 3. sınıf (\%28) öğrencileriyle yapılan çalışmaların daha fazla olduğu, 2. sınıf (\%14) ve 4. sınıf (\%6) öğrencileriyle yapılan çalışmaların ise daha az sayıda olduğu görülmüştür. İki (\%4) çalışma, 1. ile 2. ve 4. ile 5. sınıftaki öğrencilerle birlikte gerçekleştirilmiş, on iki (\%24) çalışmada ise öğrencilerin sınıf düzeyleri belirtilmemiştir.

Türkiye’de öğretmen eğitiminde PDÖ ile ilgili yapılmış araştırmaların model ve yöntemleri açısından dağılımları incelenmiş ve elde edilen bulgular Tablo 3'te sunulmuştur.

Tablo 3

Araştırmaların Model ve Yöntemleri Açısından Dă̆ılımı

\begin{tabular}{ccccccccc}
\hline & \multicolumn{3}{c}{ Model } & \multicolumn{3}{c}{ Veri toplama tekniği } \\
\hline $\begin{array}{c}\text { Betimsel } \\
\text { Tarama }\end{array}$ & Deneysel & $\begin{array}{c}\text { Betimsel ve } \\
\text { Deneysel }\end{array}$ & Belirtilmemiş & Nitel & Nicel & $\begin{array}{c}\text { Nitel ve } \\
\text { Nicel }\end{array}$ & Belirtilmemiş \\
\hline$f$ & 5 & 34 & 4 & 7 & 6 & 7 & 11 & 26 \\
\hline$\%$ & 10 & 68 & 8 & 14 & 12 & 14 & 22 & 52 \\
\hline
\end{tabular}

Tablo 3'te görüldüğü gibi, incelenen araştırmaların yarıdan fazlasında (\%68) deneysel modelin kullanıldığı görülmüştür. Bunun yanında dört çalışmada (\%8) betimsel ve deneysel model birlikte kullanılmış, yedi (\%14) çalışmanın ise modeli belirtilmemiştir. On bir araştırmada nitel ve nicel araştırma yöntemlerinin birlikte kullanıldığı (\%22 ) görülmüştür. Karma yöntemin doktora ve yüksek lisans tezlerinde kullanıldığ 1 görülmüş, 26 (\%52) araştırmada ise yöntem belirtilmemiştir.

Türkiye'de öğretmen eğitiminde PDÖ ile ilgili yapılmış araştırmaların veri toplama araçları ve teknikleri açısından dağılımları incelenmiş ve Tablo 4'te sunulmuştur. 
Tablo 4

Araştırmaların Veri Toplama Teknikleri ve Araçları Açısından Dă̆ılımı

\begin{tabular}{ccccccc}
\hline & Ölçek & Görüşme & Ölçek ve Görüşme & Gözlem & Kuramsal çalışma & Diğer \\
\hline$f$ & 31 & 3 & 12 & 5 & 7 & 32 \\
\hline$\%$ & 62 & 6 & 24 & 10 & 14 & 64 \\
\hline
\end{tabular}

Tablo 4'te görüldüğü gibi incelenen araştırmalarda veri toplama aracı olarak en çok ölçek (\%62) kullanıldığı görülmüştür. Yine araştırmalarda başarı testi, çalışma yaprağı ve senaryo gibi diğer veri toplama araçları da çok ( \%64) kullanılmıştır. Ancak gözlem $(\% 10)$ ve görüşme (\%6) ise az kullanılan veri toplama teknikleridir. Bunun yanında, araştırmaların on ikisinde (\%24) ölçek ve görüşmenin birlikte kullanıldı̆̆ 1 görülmüştür. Çalışmaların \%14'ü de kuramsal olarak üretilmiştir.

Türkiye'de öğretmen eğitiminde PDÖ ile ilgili yapılmış araştırmaların çalışılan değişkenler ve ulaşılan bulgular açısından dağılımları incelenmiş ve Tablo 5'te sunulmuştur.

Tablo 5

PDÖ ile Birlikte Çalışılan Değişkenler ve Bulgular Açısından Dă̆ılımı

\begin{tabular}{|c|c|c|c|c|c|}
\hline \multirow[b]{2}{*}{ Değişkenler } & \multirow[b]{2}{*}{$f$} & \multirow[b]{2}{*}{$\%$} & \multicolumn{3}{|c|}{ Bulgular } \\
\hline & & & Olumlu & Olumsuz & $\begin{array}{c}\text { Fark/İlişki } \\
\text { Yok }\end{array}$ \\
\hline Akademik başarı & 29 & 58 & 29 & - & - \\
\hline Tutum & 19 & 38 & 15 & - & 4 \\
\hline Bilimsel işlem süreci & 13 & 26 & 12 & - & 1 \\
\hline Problem çözme becerisi & 11 & 22 & 11 & - & - \\
\hline Yaratıcılık & 7 & 14 & 4 & - & 3 \\
\hline Motivasyon & 6 & 12 & 6 & - & - \\
\hline Öz-yeterlilik inancı & 6 & 12 & 5 & - & 1 \\
\hline Kalıcılık & 5 & 10 & 5 & - & 5 \\
\hline
\end{tabular}

Tablo 5'te görüldüğü gibi, incelenen araştırmalarda PDÖ ile çeşitli değişkenler arasındaki ilişki incelenmiştir. Araştırmalarda genellikle Tablo 5'te belirtilen değişkenler ele alındığı için bu araştırma da bu sekiz değişken ile sınırlandırılmış ve ilgili çalışmaların ne kadarında bu değişkenlerin ele alındığg incelenmiştir. Araştırmaların yarısından fazlasında (\%58) PDÖ ile akademik başarı ele alınmış ve bu araştırmaların tamamında olumlu bulgulara ulaşı1mıştır. On bir (\%22) araştırmada problem çözme becerisi, altı (\%12) araştırmada motivasyon, beş (\%10) araştırmada ise, 
öğrenmede kalıcılık değişkenleri ele alınmış, bu değişkenlerle PDÖ arasındaki ilişkiler sonucunda ilgili araştırmaların tamamında olumlu bulgulara ulaşılmıştır.

Araştırmaların on dokuzunda tutum (\%38) değişkeni ele alınmış bunun sonucunda, on beş çalışmada olumlu, dört çalışmada da farkın olmadığı bulgusuna ulaşılmıştır. Araştırmaların altısında öz-yeterlilik inancı (\%12), on üçünde bilimsel işlem süreci (\%26) değişkenleri ele alınmış bunun sonucunda sadece birer çalışmada farkın olmadığı bulgusuna ulaşılmıştır. Yaratıcılık değişkeni ise yedi (\%14) araştırmada ele alınmış, bunun sonucunda dört araştırmada olumlu, üç araştırmada farkın olmadığ bulgusuna ulaşılmıştır. Araştırmalarda ele alınan sekiz değişkenin PDÖ ile arasındaki ilişkilerin incelenmesi sonucunda hiçbir olumsuz bulguya ulaş1lmamıştır. İncelenen araştırmalarda PDÖ'nin söz konusu değişkenler üzerinde genellikle olumlu etkilerinin olduğu bulgularına ulaşıldığı görülmüştür.

\section{Sonuç ve Tartışma}

Araştırmada Türkiye’de öğretmen eğitiminde PDÖ ile ilgili yapılmış çalışmaların değerlendirilmesi amaçlanmıştır. Bu amaç doğrultusunda 2002-2013 yılları arasında öğretmen eğitiminde PDÖ’ye ilişkin yapılmış, 23 makale (\%46), 11 yüksek lisans tezi $(\% 22)$ ve 16 doktora tezine (\%32) ulaşılmıştır. PDÖ ile ilgili çalışmaların yaklaşık yarıya yakını makale olarak gerçekleştirilmiş olup, yarıdan daha azı yüksek lisans tezi, yaklaşık üçte biri doktora tezi olarak yapılmıştır. Öğretmen eğitiminde PDÖ’ye ilişkin yapılan araştırmaların 2005-2012 yılları arasında yoğunlaştığı görülmüştür. Bunun nedeninin, Türkiye'de 2005 yılından bu yana, yapılandırmacı anlayışa dayalı olarak yenilenen ilköğretim programları ile birlikte bu anlayışa uygun öğretim modellerinin uygulanmaya çalışılması olduğu düşünülebilir. Çünkü eğitim programları yenilenerek geleneksel öğrenme ortamlarından yapılandırmacı öğrenme ortamlarına geçilmesi amaçlanmıştır (Ocak, 2012). Nitekim bu doğrultuda, Türkiye'de son yıllarda yapılan çalışmalarda öğretmen eğitiminde yapılandırmacı öğrenme yaşantılarının yararlarına, öğretmen adayları üzerindeki olumlu etkilerine işaret edilmekte ve öğretmen eğitimi programlarının yapılandırmacı anlayışla geliştirilmesi gerektiği vurgulanmaktadır (Bukova-Güzel, 2008; Kardaş, 2014; Oğuz, 2009). Araştırmada, 2002-2004 yılları arasında birer çalışmaya ulaşılmıştır. Bu durum, 2004 yılından önce Türkiye'de yapılandırmacı anlayışın çok fazla gündemde olmamasından kaynaklanmış olabilir ve bu nedenle, bu yıllarda diğer yıllara göre daha az çalışma yapılmış olabileceği düşünülebilir. 2013 yılında da bu konuda yapılmış çok az araştırmaya rastlanmıştır. Bunun nedeni, araştırmanın gerçekleştirildiği tarihlerde 2013 yılında ait bazı makalelerin henüz yayımlanmamış olmasından kaynaklanmış olabilir.

Öğretmen eğitiminde PDÖ’ye yönelik incelemeye alınan araştırmaların tamamına yakınının (\%88) öğrencilerle, iki (\%4) araştırmanın öğretmenlerle ve dört (\%) araştırmanın da doküman incelemesi ya da kuramsal olarak gerçekleştirildiği görülmüştür. Araştırmaların çoğunlukla öğrencilerle (öğretmen adaylarıyla) gerçekleştirilmesinin nedeni, onlara ulaşma kolaylığı olabilir. Ayrıca, araştırmaların hizmet öncesinde mesleğe başlanmadan yapılıp ulaşılan sonuçların mesleğe 
başlandıktan sonra kullanılmasını sağlamak ve böylece nitelikli öğretmenler yetiştirmek amaçlanmış olabilir.

İncelenen araştırmalarda örneklem grubu olarak öğrencilerle yürütülen 44 çalışmada en çok araştırmanın Fen Bilgisi Öğretmenliği (\%32) programında yapıldı̆̆ı, bunu Sınıf Öğretmenliği (\%16) ve Matematik Öğretmenliği (\%12) programlarının izlediği; Resim Öğretmenliği, Beden Eğitimi Öğretmenliği, Tarih Öğretmenliği, Coğrafya Öğretmenliği, Biyoloji Öğretmenliği, Okul Öncesi Öğretmenliği programlarında ise hiç çalışma yapılmadığı belirlenmiştir. Türkçe Öğretmenliği, İngilizce Öğretmenliği, Sosyal Bilgiler Öğretmenliği ve Fizik Öğretmenliği bölümlerinde ise sadece ikişer araştırma yapıldığı görülmüştür. Bu durum, Fen Bilgisi, Sınıf ve Matematik öğretmenliği dışındaki öğretmen eğitimi programlarında PDÖ konusunda araştırma yapılmasına gereksinim olduğuna işaret etmektedir. Ayrıca araştırmaların yine tamamına yakınının (42) sadece bir programda öğrenim gören öğrencilerle gerçekleştirildiği ve üç çalışmanın iki programın öğrencileriyle birlikte ortak olarak gerçekleştirildiği görülmüştür. Farklı öğretmenlik programlarıyla birlikte daha fazla araştırmalar yürütülebilir ve karşılaştırmalar yapılabilir. Öğretmenlerle gerçekleştirilen iki çalışmanın da Sınıf ve Matematik öğretmenleriyle gerçekleştirildiği belirlenmiştir. Bu bulgulara göre, öğretmenlerle yapılan çalışmaların çok az sayıda olduğu öğretmenlerle daha fazla çalışılmasına ve özellikle de Sınıf ve Matematik öğretmenleri dışında diğer branşlardaki öğretmenlerle de bu konuyla ilgili çalışmaların hizmet içinde yapılmasına gereksinim olduğu söylenebilir. Nitekim öğretmenlerin düzenledikleri yapılandırmacı öğrenme ortamlarının yeterli olmadığına işaret eden araştırma bulguları (Ocak, 2012) da öğretmenlerin bu konuda yetiştirilmesi gerektiğine işaret etmektedir.

İncelenen araştırmaların sınıf düzeyleri incelendiğinde; daha çok 1. sınıf (\%24) ve 3. sınıf (\%28) öğrencileriyle çalışmaların yapıldığı; 2. sınıf (\%14) ve 4. sınıf (\%6) öğrencileriyle daha az çalışıldığı görülmüştür. İki (\%4) çalışmada farklı sınıf düzeylerindeki öğrencilerle birlikte çalışıldığı belirlenmiştir. Bu bulgulara göre özellikle 2. ve 4. sınıf ögrrencileriyle de bu konuda daha fazla çalışmanın yapılması gerektiği belirtilebilir.

Araştırmaların yarıdan fazlasında deneysel modelin (\%68) kullanıldığı ve beş araştırmada da tarama modelinin kullanıldı̆̆ı görülmüştür. Bunun yanında dört çalışmada (\%8) betimsel ve deneysel model birlikte kullanılmış, yedi (\%14) çalışmanın ise modeli belirtilmemiştir. Benzer şekilde, Bıkmaz Hazır, Aksoy ve Tatar'ın (2010) eğitimde program geliştirme alanında yapılan doktora tezlerini çeşitli değişkenlere göre analiz etmek amacıyla yaptığı araştırmada deneysel ve betimsel çalışmaların çok daha fazla tercih edildiği ortaya çıkmıştır. Karadağ'ın (2009) yaptığı çalışmada da 211 doktora tez çalışmasında deneysel ve tarama modellerinin en sık kullanılan modeller olduğu belirlenmiştir. PDÖ ortamının çeşitli değişkenler üzerindeki etkisinin ya da uygulanmasının incelenmesi deneysel araştırmayı gerekli kıldığı için araştırmalarda deneysel modelin daha fazla kullanılması doğal görülebilir. Araştırmalarda hem deneysel hem de betimsel çalışmaların birlikte kullanılabileceği çalışmalara daha fazla 
yer verilebilir. İncelenen araştırmaların beşte birinde nitel ve nicel (karma) araştırma yönteminin, doktora ve yüksek lisans tezlerinde birlikte kullanıldığı bulgusu dikkate alındığında, nitel ve nicel çeşitli veri toplama tekniklerinin birlikte kullanıldığı çalışmalara gereksinim olduğu söylenebilir.

İncelemeye alınan araştırmaların yarıdan fazlasında (\%62) veri toplama aracı olarak en çok ölçek kullanıldığ görülmüştür. Buna benzer olarak Kazu ve Aslan'ın (2013) ilköğretim programının ölçme-değerlendirme boyutu ile ilgili yapılan çalı̧̧maları değerlendirmek amacıyla yaptığı çalışmada da benzer şekilde, makalelerde en fazla anketin kullanıldığı belirtilmektedir. Saracaloğlu ve Dursun'un (2010) Türkiye’deki eğitim programları ve öğretim ana bilim dalında yüksek lisans ve doktora düzeyinde yapılan tezlerdeki araştırma eğilimlerini ortaya çıkarmak amacıyla yaptığı araştırmada da en çok anket, başarı testi, kişisel bilgi formu, tutum ölçeği, ön test, son test gibi ölçme araçlarıyla bilgi toplandığı saptanmıştır. Nitekim anketin, diğer veri toplama tekniklerine (görüşme, gözlem vs.) göre farklı bölgelerden çok daha büyük gruplara hızlı uygulama olanağının olması ve maliyetinin daha düşük olması gibi avantajlara sahip olduğu belirtilmektedir (Büyüköztürk \& diğ., 2013). Bu nedenle, araştırmalarda daha çok anket tercih edilmiş olabilir. Yine incelemeye alınan araştırmaların yarıdan fazlasında (\%64) başarı testi, çalışma yaprağı ve senaryo gibi diğer veri toplama araçlarının da kullanıldığı belirlenmiştir. Gözlem (\%10) ve görüşme (\%6) ise daha az kullanılan veri toplama araçlarıdır. Bunun yanında araştırmaların on ikisinde (\%24) ölçek ve görüşmenin birlikte kullanıldı̆̆g görülmüştür. Yine bu konuda çalışılan kuramsal araştırma (\%14) sayısı da oldukça azdır. Bu bulgulara göre özellikle görüşmeye ve gözleme dayalı daha fazla çalışmaların yapılmasına gereksinim olduğu söylenebilir.

Araştırmalarda; PDÖ ile çeşitli değiş̧kenler arasındaki ilişkinin incelendiği görülmüştür. Genellikle "akademik başarı, motivasyon, tutum, problem çözme becerisi, öz-yeterlilik inancı, bilimsel işlem süreci, yaratıcılık ve kalıclık" gibi değişkenlerin ele alındığı belirlenmiştir. Araşıırmaların yarıdan biraz fazlasında (\%58) PDÖ ile akademik başarı incelenmiş ve bu araştırmaların tamamında olumlu bulgulara ulaşılmıştır. Başka bir anlatımla, PDÖ'ye yönelik uygulamaların başarıyı olumlu yönde etkilediği görülmüştür. Örneğin Gürlen (2011), öğretmen adaylarına yönelik yaptığı çalışmada probleme dayalı öğrenmenin öğrenen başarısında daha etkili olduğu sonucuna ulaşmıştır. Karadağ (2009) tarafindan gerçekleştirilen çalışmada da benzer şekilde, Türkiye'de eğitim bilimleri alanında yapılmış doktora tezlerinde başarı ve tutum temasına yoğunlaşıldığı sonucuna ulaşılmıştır.

İncelenen on bir araştırmada problem çözme becerisi (\%22), altı araştırmada motivasyon (\%12), beş araştırmada da öğrenmede kalıcılık (\%10) değişkenleri ele alınmış, bu değiş̧kenlerle PDÖ arasındaki ilişkilerin incelenmesi sonucunda ilgili araştırmaların tamamında olumlu bulgulara ulaşıldığı belirlenmiştir. Araştırmalarda PDÖ'nin problem çözme becerisini, motivasyonu ve kalıcılığı olumlu yönde etkilediği görülmüştür. Araştırmaların on dokuzunda tutum (\%38) değişkeni ele alınmış bunun sonucunda on beş çalışmada olumlu, dört çalışmada da farkın olmadığı bulgusuna 
ulaşılmıştır. Araştırmaların altısında öz-yeterlilik inancı (\%12), on üçünde bilimsel işlem süreci (\%26) değişkenleri ele alınmış bunun sonucunda sadece birer çalışmada farkın olmadığı bulgusuna ulaşılmıştır. PDÖ ile yaratıcılık değişkeni ise yedi (\%14) araştırmada ele alınmış, bunun sonucunda dört araştırmada olumlu, üç araştırmada farkın olmadığı bulgusuna ulaşılmıştır. İncelenen araştırma bulgularına göre genel olarak, PDÖ uygulamalarının yukarıda belirtilen değişkenler üzerinde olumlu etkiler bıraktığı söylenebilir. Ancak bazı araştırmalarda farkın/ilişkinin olmadığı da dikkate alınırsa, duruma daha fazla açıklık getirebileceği düşünülerek bu değişkenlerle ilgili daha fazla araştırma bulgusuna gereksinim olduğu söylenebilir.

\section{Öneriler}

Araştırmada elde edilen sonuçlara dayalı olarak aşağıdaki öneriler getirilebilir:

- Türkiye'de gerçekleştirilen yüksek lisans ve doktora tezlerinde PDÖ’ye ilişkin daha fazla çalışmalar yapılabilir.

- PDÖ’ye ilişkin araştırmaların, çoğunlukla öğrencilerle (öğretmen adaylarıyla) gerçekleştirildiği dikkate alınırsa, öğrencilerin yanı sıra, öğretmenlerle ve öğretmen eğitimcileriyle de gerçekleştirilmesi düşünülebilir.

- Bu konudaki araştırmalar, Fen Bilgisi Öğretmenliği, Sınıf Öğretmenliği ve Matematik Öğretmenliği programlarının yanı sıra; Resim Öğretmenliği, Beden Eğitimi Öğretmenliği, Tarih Öğretmenliği, Coğrafya Öğretmenliği, Biyoloji Öğretmenliği, Okul Öncesi Öğretmenliği, Türkçe Öğretmenliği, İngilizce Öğretmenliği, Sosyal Bilgiler Öğretmenliği ve Müzik Öğretmenliği gibi diğer öğretmen eğitimi programlarının tüm sınıf düzeylerinde farklı örneklem gruplarında da yapılabilir.

- Araştırmalarda deneysel araştırma modelinin yanı sıra farklı araştırma modellerine; nitel ve nicel veri toplama tekniklerinin birlikte kullanıldığı çalışmalara yer verilebilir.

- PDÖ ortamlarında gözlem ve görüşme tekniklerine dayalı verilerin toplandığı çalışmalar yapılabilir.

- Araştırmalarda; PDÖ’ye ilişkin başta akademik başarı olmak üzere; motivasyon, tutum, problem çözme becerisi, öz-yeterlilik inancı, bilimsel işlem süreci, yaratıcılık ve kalıcılık gibi değişkenlerin incelendiği göz önüne alındığında; bu değişkenlerin dışında, PDÖ’yi öz düzenleme becerisi, ders çalışma becerisi, öğrenme stili, öğrenme stratejileri gibi daha farklı değişkenlerle ilişkilendiren çalışmalar da gerçekleştirilebilir.

\section{Kaynakça}

Alagöz, B. (2009). Sosyal bilgiler öğretmen adaylarında çevre bilincinin geliştirilmesinde probleme dayalı öğrenme yönteminin etkisi (Yayımlanmamış Doktora Tezi). Gazi Üniversitesi, Eğitim Bilimleri Enstitüsü, Ankara.

Bıkmaz Hazır, F., Aksoy, E., \& Tatar, Ö. (2010). Türkiye'de program geliştirme alanında yapılan doktora tezlerinin çeşitli değişkenler açısından analizi. I. Ulusal 
Eğitim Programlanı Öğretim Kongresi Bildiri, http://www.pegem.net/akademi/kongrebildiri_detay.aspx?id=117913. (Erişim Tarihi: 02.12.2014)

Brooks, M. G. \& Brooks, J. G. (1999). The constructivist classroom: The courage to be constructivist. Educational Leadership, 57(3), 18-24.

Bukova-Güzel, E. (2008). Yapılandırmacı öğrenme yaklaşımının matematik öğretmen adaylarının matematiksel düşünme süreçlerine olan etkisi. E-Journal of New World Sciences Academy, 3(4), 678-688.

Büyüköztürk, Ş., Kılıç Çakmak, E., Akgün, Ö.E., Karadeniz, Ş., \& Demirel, F. (2013). Bilimsel araştırma yöntemleri, (15. Baskl). Ankara: Pegem Akademi Yayıncılık.

Çelik, P. (2013). Probleme dayalı ögrenmenin öğretmen adaylarının fizik dersi başarısı, öğrenme yaklaşımları ve bilimsel süreç becerileri üzerindeki etkisi. (Yayımlanmamış Doktora Tezi). Dokuz Eylül Üniversitesi, Eğitim Bilimleri Enstitüsü, İzmir.

Demirel, M. \& Arslan Turan, B. (2010). Probleme dayalı öğrenmenin başarıya tutuma bilişötesi farkındalık ve güdü düzeyine etkisi. Hacettepe Üniversitesi Ĕgitim Fakültesi Dergisi, 38, 55-66.

Edwards, S. \& Hammer, M. (2006). Laura’s story: Using problem based learning in early cildhood and primary teacher education, Teaching and Teacher Education, 22, 465-477.

Erdem, E. (2006). Probleme dayalı öğrenmenin öğrenme ürünlerine, problem çözme becerisine ve öz-yeterlik algl düzeyine etkisi (Yayımlanmamış Doktora Tezi). Hacettepe Üniversitesi, Sosyal Bilimler Enstitüsü, Ankara.

Erdem, E. (2007). Probleme dayalı öğrenme. Özcan Demirel (Ed.), Eğitimde yeni yönelimler. Ankara: Pegem Akademi Yayıncılık.

Erdoğan, T. 2012. Probleme dayalı öğrenmenin erişiye ve öz-düzenleme becerilerine etkisi (Yayımlanmamış Doktora Tezi). Hacettepe Üniversitesi, Sosyal Bilimler Enstitüsü, Ankara.

Erdoğan, T. \& Senemoğlu, N. (2014). Problem-based learning in teacher education: Its promises and challenges. Procedia-Social and Behavioral Sciences, 116, 459-463.

Fettahoğlu, P. (2012). Fen bilgisi ögretmeni adaylarının çevre okuryazarılı̆̆ının geliştirilmesine yönelik olarak argümantasyon ile probleme dayalı ögrenme yaklaşımının kullanımı (Yayımlanmamış Doktora Tezi). Gazi Üniversitesi, Eğitim Bilimleri Enstitüsü, Ankara.

Gabler, I. C. \& Schroeder, M. (2003). Seven constructivist methods for the secondary classroom: A planning guide for invisible teaching. USA: Pearson Education, Inc.

Gagnon, G. W. \& Collay, M. (2001). Designing for learning six elements in constructivist classrooms. Thousand Oaks, California: Corwin Pres, Inc. 
Gürlen, E. (2011). Probleme dayalı öğrenmenin öğrenme ürünlerine, problem çözme becerilerine, öz-yeterlik alg1 düzeyine etkisi. Hacettepe Üniversitesi Ĕ̆itim Fakültesi Dergisi [H. U. Journal of Education], 40, 221-232.

Jofili, Z., Geraldo, A. \& Watts, M. (1999). A course for critical constructivism through action research: A case study from biology. Research in Science \& Technological Education. 17, 1; ProQuest Education Journals, 5-17.

Jonassen, D. H. (2006). A constructivist's perspective on functional contextualism. Educational Technology, Research and Development, 54, 1; ProQuest Education Journals, 43-47.

Kaptan, F. \& Korkmaz, H. (2001). Fen eğitiminde probleme dayalı öğrenme yaklaşımı. Hacettepe Üniversitesi Ë̆itim Fakültesi Dergisi, 20, 185 -192.

Karadağ, E. (2009). Eğitim bilimleri alanında yapılmış doktora tezlerinin tematik açıdan incelemesi. Ahi Evran Üniversitesi Eğitim Fakültesi Dergisi, 10(3), 75-87.

Kardaş, M. N. (2014). Türkçe öğretmeni adaylarının yapılandırmacı öğretim yaklaşımıyla ilgili farkındalık ve yeterlikleri. Uluslar Arası Sosyal Araştırmalar Dergisi, 7(34), 779-791.

Kazu , H. \& Aslan, S. (2013). 2004 ilköğretim programının “ölçme-değerlendirme” boyutu ile ilgili yapılan araştırmaların değerlendirilmesi. İlkögretim Online, 12(1), 87-108. http://ilkogretim-online.org.tr, (Erişim tarihi: 25.01.2014).

Maxwell, N. L., Bellisimo, Y., \& Mergendoller, J. (2001). Problem - based learning: modifying the medical school model for teaching high school economics. The Social Studies, March/April, 73-78.

McPhee, A. D. (2002). Problem-based learning in initial teacher education: Taking the agenda forward. Journal of Educational Enquiry, 3(1), 60-78.

Ocak, G. (2012). Öğretmenlerin yapılandırmacı öğrenme ortamı kurma başarılarının öğretmen ve öğretmen adaylarınca değerlendirilmesi. Ĕgitim ve Bilim, 37(166), 2540.

Oğuz, A. (2009). Öğretmen eğitimi programlarındaki uygulamaların yapılandırmacı yaklaşıma uygunluğunun öğretmen adayı görüşleriyle değerlendirilmesi. Ankara Üniversitesi Eğitim Bilimleri Fakültesi Dergisi, 42(1), 129-155.

Olsen, D. G. (1999). Constructivist principles of learning and teaching methods. Education, 120(2), 347-355.

Patrick, F. \& McPhee, A. (2014). Evaluating the use of problem-based learning in a new initial teacher education degree. TEAN Journal, 6(2), 3-12.

Plourde, L. A. \&, Alawiye, O. (2003). Constuctivism and elementary preservice science teacher preparation: Knowledge to application. College Student Journal, 37(3), 334-341.

Saban, A. (2009). Öğrenme ögrretme süreci: Yeni teori ve yaklaşımlar, (5. Bask1). Ankara: Nobel Yayın Dağıtım. 
Saracaloğlu, S. \& Dursun, F. (2010). Türkiye'de eğitim programlarl ve ögretim alanındaki lisansüstü tezlerinin incelenmesi. I. Ulusal Eğitim Programlan ve Öğretim Kongresi Bildiri,http://www.pegem.net/akademi/kongrebildiri_detay.aspx?id=117909. (Erişim Tarihi: 02.12.2014)

Senemoğlu, N. (2013). Gelişim öğrenme ve öğretim: Kuramdan uygulamaya, (23. Bask1). Ankara: Yarg1 Yayınevi.

Simone, C. D. (2008). Problem-based learning: A framework for prospective teachers' pedagogical problem solving. Teacher Development, 12(3), 179-191.

Şendağ, S. (2008). Çevrimiçi probleme dayalı öğrenmenin öğretmen adaylarının eleştirel düşünme becerilerine ve akademik başarılarına etkisi (Yayımlanmamış Doktora Tezi). Anadolu Üniversitesi, Eğitim Bilimleri Enstitüsü, Eskişehir.

Tynjälä, P. (1999). Towards expert knowledge? A comparison between a constructivist and a traditional learning environment in the university. International Journal of Educational Research, 31, 357-442.

Ün Açıkgöz, K. (2002). Aktif öğrenme. İzmir: Eğitim Dünyası Yayınları.

Windschitl, M. (1999). The challenges of sustaining a constructivist classroom culture. Phi Delta Kappan, 80(10), 751-755.

Yager, R. E. (1991). The constructivist learning model towards real reform in science education. The Science Teacher, National Science Teachers Association, 58(6), 5257.

Yıldırım, A., \& Şimşek, H. (1999). Sosyal bilimlerde nitel araştırma yöntemleri. Ankara: Seçkin Yayınevi. 